\title{
Radiation Macular Edema after Ru-106 Plaque Brachytherapy for Choroidal Melanoma Resolved by an Intravitreal Dexamethasone 0.7-mg Implant
}

\author{
Andrea Russo Teresio Avitabile Maurizio Uva \\ Salvatore Faro Livio Franco Marisa Sanfilippo \\ Seby Gulisano Mario Toro Vittorio De Grande \\ Stefania Rametta Laura Foti Antonio Longo \\ Michele Reibaldi
}

Department of Ophthalmology, University of Catania, Catania, Italy

\section{Key Words}

Choroidal melanoma $\cdot$ Ru-106 plaque - Macular edema · Dexamethasone $0.7 \mathrm{mg} \cdot$ Ozurdex ${ }^{\circledR}$

\begin{abstract}
Purpose: To report the effective treatment of radiation macular edema following ruthenium106 plaque brachytherapy for a choroidal melanoma with a dexamethasone 0.7-mg (Ozurdex ${ }^{\circledR}$ ) intravitreal implant.

Methods: An interventional case report with optical coherence tomography (OCT) scans.

Results: A 65-year-old Caucasian woman was suffering from radiation macular edema following ruthenium-106 plaque brachytherapy for a choroidal melanoma on her left eye. She had undergone one intravitreal injection of $0.5 \mathrm{mg}$ bevacizumab (Avastin ${ }^{\circledR}$, Genentech/Roche) in the following months without functional or anatomical improvement. Seven months after the development of radiation macular edema, she received a single intravitreal injection of dexamethasone $0.7 \mathrm{mg}$ (Ozurdex). Four weeks following the injection, her best-corrected visual acuity improved from 0.3 to 0.5 . Radiation macular edema resolved with a reduction of central retinal thickness from $498 \mu \mathrm{m}$ before Ozurdex injection to $224 \mu \mathrm{m}$ after Ozurdex injection, as measured by OCT scan.
\end{abstract}

Conclusion: Dexamethasone $0.7 \mathrm{mg}$ (Ozurdex) has proven to be an effective treatment option in retinal vein occlusion and noninfectious uveitis. It can also be considered as off- 
label treatment in radiation macular edema following ruthenium-106 plaque brachytherapy for a choroidal melanoma.

\section{Introduction}

Radiation retinopathy is a predictable complication after radioactive scleral plaque application for treatment of intraocular tumors, most commonly choroidal melanoma [1]. Macular edema is a common manifestation of radiation retinopathy that may lead to severe visual loss. According to Guyer et al. [2], it was the most frequent and early finding after proton beam therapy for paramacular choroidal tumors, with $87 \%$ of 218 patients who developed macular edema. Other studies suggest rates of radiation maculopathy from plaque radiotherapy of 18\% [3], 23\% [4], and 42.8\% [5]. Different treatment modalities for macular edema have been reported. These include laser photocoagulation [6], photodynamic therapy [7], pentoxifylline [8] and intravitreal bevacizumab $[9,10]$.

Corticosteroids are potent anti-inflammatory agents that can counteract many of the pathological processes thought to play a role in the development of macular edema. Recently, a sustained-release dexamethasone implant $\left(\mathrm{Ozurdex}^{\circledR}\right)$ proved to be effective for the treatment of macular edema secondary to a variety of underlying diseases with a potentially lower rate of adverse events [11].

There are no cases of radiation macular edema after ruthenium $(\mathrm{Ru})-106$ plaque brachytherapy for choroidal melanoma resolved by an intravitreal dexamethasone 0.7 mg implant described so far in the literature.

We report a case of radiation macular edema after Ru-106 brachytherapy for a choroidal melanoma, refractory to a previous treatment with intravitreal bevacizumab, and resolved with significant improvement of visual function following an intravitreal injection of dexamethasone $0.7 \mathrm{mg}$.

\section{Case Report}

A 65-year-old Caucasian woman developed radiation macular edema 24 months following Ru-106 plaque brachytherapy for a choroidal melanoma on her left eye (fig. 1a). She underwent one intravitreal injection of $0.5 \mathrm{mg}$ bevacizumab (Avastin ${ }^{\circledR}$, Genentech/Roche) in the following months without functional or anatomical improvement. Seven months after the development of radiation macular edema, she received a single intravitreal injection of dexamethasone $0.7 \mathrm{mg}$ (Ozurdex) as offlabel treatment. Four weeks following the injection, her best-corrected visual acuity (BCVA) improved from 0.3 to 0.5 . The radiation macular edema resolved (fig. $1 \mathrm{~b}$ ) with a reduction of central retinal thickness from $498 \mu \mathrm{m}$ before Ozurdex injection (fig. 2a) to $224 \mu \mathrm{m}$ after Ozurdex injection (fig. 2b), as measured by optical coherence tomography (OCT) scan. Her condition has been stable for at least 5 months now, as seen on the last examination, with BCVA 0.6 and resolved macular edema in the treated eye. No complications were observed. 


\section{Discussion}

Shields et al. [12] reported the use of intravitreal triamcinolone $(4 \mathrm{mg} / \mathrm{ml})$ in a prospective, nonrandomized, single-center case series of 31 patients with visually symptomatic radiation-induced macular edema after plaque radiotherapy. They reported that visual acuity was stable or improved in $91 \%$ of patients by one month and $45 \%$ by six months; they also found a decrease in the mean central subfield foveal thickness measured by OCT. Despite the potential benefits, intravitreal injection of triamcinolone acetate is associated with side effects, including glaucoma, cataracts, retinal detachment, and endophthalmitis $[13,14]$.

Also intravitreal bevacizumab has been evaluated as a treatment option for radiation maculopathy secondary to plaque radiotherapy $[9,10]$. Our patient was initially treated with an intravitreal injection of bevacizumab which has not proved effective. Gupta et al. [9] stated that intravitreal injection of bevacizumab for treatment of radiation maculopathy caused by plaque radiotherapy was not useful for long-standing macular edema or when direct irradiation was received by the fovea.

One of the main mechanisms of the chronic macular edema is the alteration of Muller cells functionality; it has been experimentally shown that steroids, by reducing the osmotic swelling of the Muller's cells, improve their functionality and reduce the macular edema [15].

This could indicate that dexamethasone implant (Ozurdex) might be an effective treatment option not only in retinal vein occlusion and noninfectious uveitis, but can also be considered as off-label treatment in radiation macular edema after $\mathrm{Ru}-106$ plaque brachytherapy for choroidal melanoma.

\section{Disclosure Statement}

The authors have no conflicts of interest to declare. 

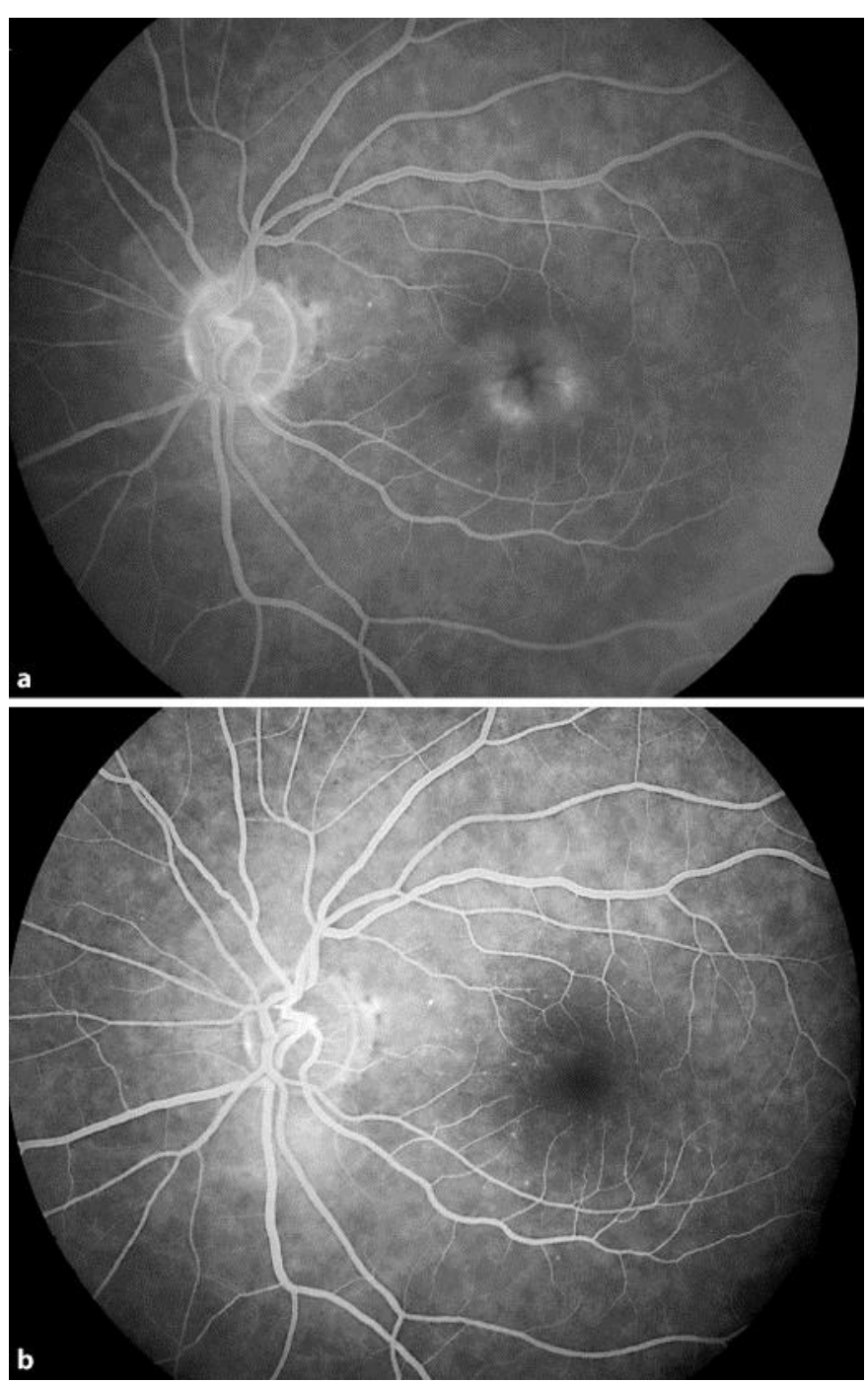

Fig. 1. a Fluorescein angiography before Ozurdex injection. b Fluorescein angiography four weeks following the injection of Ozurdex. 

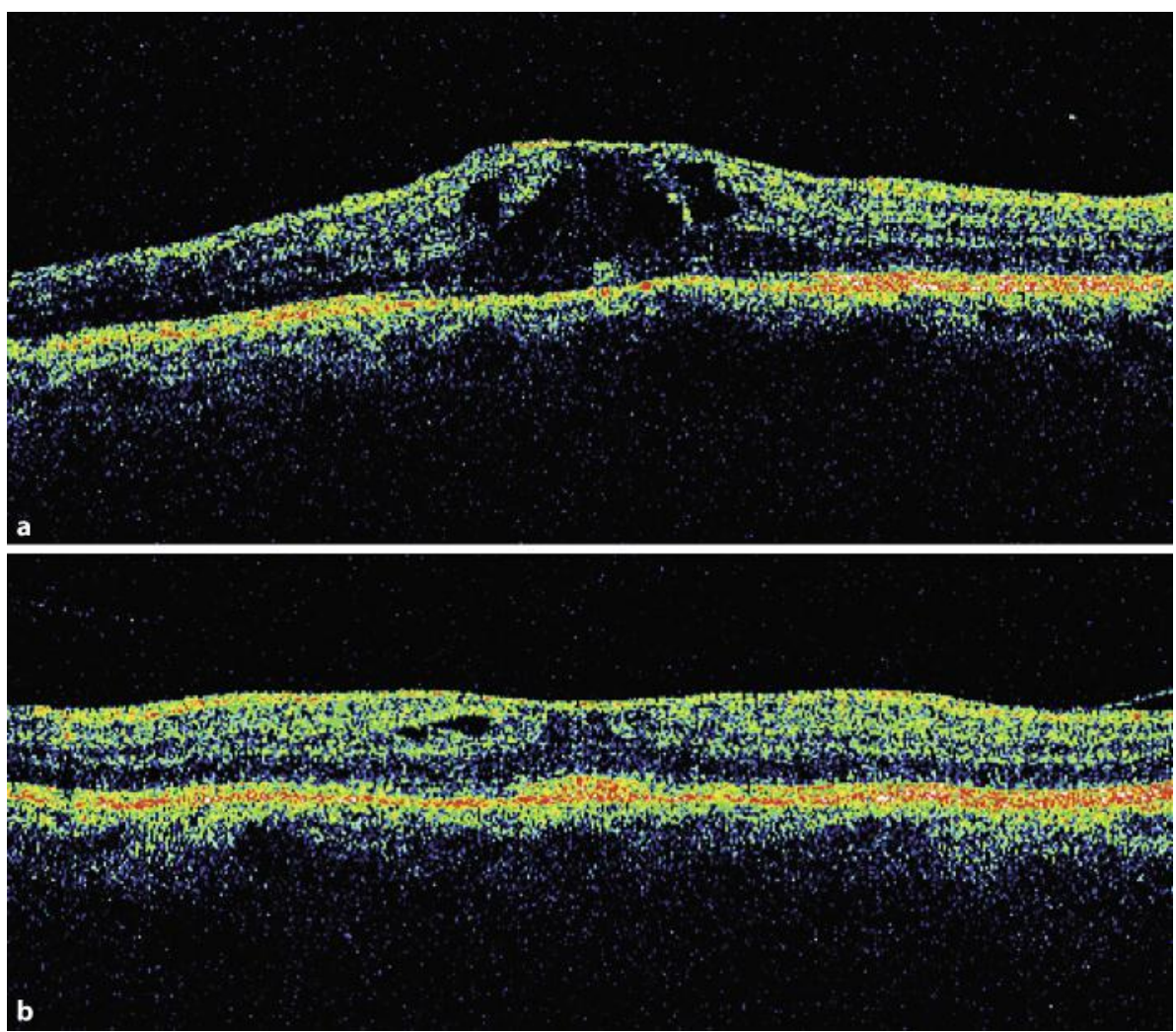

Fig. 2. a OCT before Ozurdex injection; central retinal thickness was $498 \mu \mathrm{m}$. b OCT four weeks after the injection of Ozurdex; central retinal thickness was $224 \mu \mathrm{m}$.

\section{References}

1 Gündüz K, Shields CL, Shields JA, Cater J, Freire JE, Brady LW: Radiation complications and tumor control after plaque radiotherapy of choroidal melanoma with macular involvement. Am J Ophthalmol 1999;127:579-589.

-2 Guyer DR, Mukai S, Egan KM, Seddon JM, Walsh SM, Gragoudas ES: Radiation maculopathy after proton beam irradiation for choroidal melanoma. Ophthalmology 1992;99:1278-1285.

-3 Quivey JM, Char DH, Phillips TL, Weaver KA, Castro JR, Kroll SM: High intensity 125 iodine plaque treatment of uveal melanoma. Int J Radiat Oncol Biol Phys 1993;26:613-618.

4 Haye C, Desjardins L, Bouder P, Schlienger P, Dorval T: Maculopathy caused by irradiation in patients treated for choroid melanoma. Ophtalmologie 1990;4:229-231.

-5 Gunduz K, Shields CL, Shields JA, et al: Radiation retinopathy following plaque radiotherapy for posterior uveal melanoma. Arch Ophthalmol 1999;117:609-614.

6 Hykin PG, Shields CL, Shields JA, Arevalo JF: The efficacy of focal laser therapy in radiation-induced macular edema. Ophthalmology 1998;105:1425-1429.

7 Bakri SJ, Beer PM: Photodynamic therapy for maculopathy due to radiation retinopathy. Eye 2005;19:795-799.

8 Gupta P, Meisenberg B, Amin P, Pomeranz H: Radiation retinopathy: the role of pentoxifylline. Retina 2001;21:545-547.

-9 Gupta A, Muecke JS: Treatment of radiation maculopathy with intravitreal injection of bevacizumab (Avastin). Retina 2008;28:964-968.

10 Mason J0 3rd, Albert MA Jr, Persaud TO, Vail RS: Intravitreal bevacizumab treatment for radiation macular edema after plaque radiotherapy for choroidal melanoma. Retina 2007;27:903-907. 
11 Herrero-Vanell R, Cardillo JA, Kuppermann BD: Clinical applications for the sustained-release dexamethasone implant for treatment of macular edema. Clin Ophthalmol 2011;5:139-146

-12 Shields CL, Demirci H, Dai V, Marr BP, Mashayekhi A, Materin MA, Manquez ME, Shields JA: Intravitreal triamcinolone acetonide for radiation maculopathy after plaque radiotherapy for choroidal melanoma. Retina 2005;25:868-874

13 Gillies MC, Sutter FK, Simpson JM, Larsson J, Ali H, Zhu M: Intravitreal triamcinolone for refractory diabetic macular edema: Two-year results of a double-masked, placebo controlled, randomized clinical trial. Ophthalmology 2006;113:1533-1538.

14 Conti SM, Kertes PJ: The use of intravitreal corticosteroids, evidence-based and otherwise. Curr Opin Ophthalmol 2006;17:235-244.

15 Reibaldi M, Russo A, Zagari M, Toro M, De Grande V, Cifalinò V, Rametta S, Faro S, Longo A: Resolution of persistent cystoid macular edema due to central retinal vein occlusion in a vitrectomized eye following intravitreal implant of dexamethasone $0.7 \mathrm{mg}$. Case Rep Ophthalmol 2012; article in press. 